\title{
Radical perineal prostatectomy: Our initial experience
}

\author{
Mustafa Güneş ${ }^{1}$, Mehmet Akyüz ${ }^{2}$, Fatih Uruç ${ }^{3}$, Bekir Aras $^{4}$, Muammer Altok ${ }^{1}$, Mehmet Umul $^{1}$
}

${ }^{1}$ Department of Urology, Süleyman Demirel University Faculty of Medicine, Isparta, Turkey

${ }^{2}$ Clinic of Urology, Haydarpaşa Numune Training and Research Hospital,

İstanbul, Turkey

${ }^{3}$ Clinic of Urology, Fatih Sultan Mehmet Training and Research Hospital, Istanbul, Turkey

${ }^{4}$ Department of Urology, Dumlupınar University Evliya Çelebi Training and Research Hospital, Kütahya, Turkey

Submitted: 23.09.2013

Accepted:

14.01.2014

Correspondence:

Mustafa Güneş, MD,

Department of Urology,

Süleyman Demirel University

Faculty of Medicine,

Isparta, Turkey

Phone: +902462119321

E-mail: mustafagunes@sdu.edu.tr

(C) Copyright 2014 by Turkish

Association of Urology

Available online at

www.turkishjournalofurology.com

\begin{abstract}
Objective: Radical prostatectomy is the standard treatment modality for localized prostate cancer. Minimally invasive surgery, especially robotic surgery, has attracted interest in the last 10 years, and open surgery has been less preferred. Among the open surgical procedures, the perineal approach is the least preferred by urologists, which may be related to their perception of its overall difficulty. In this study, we aimed to present our initial experience with learning and performing radical perineal prostatectomy (RPP) and to draw attention to this method.
\end{abstract}

Material and methods: After a short training period between November 2011 and May 2013, RPP was performed on 9 patients with localized prostate cancer. The patients were evaluated as for medical, and perioperative and major postoperative complications.

Results: The mean age of the patients was $60.4 \pm 5.3$ (50-68) years, the mean preoperative prostate-specific antigen (PSA) value was $5.8 \pm 1.3(4.0-7.6) \mathrm{ng} / \mathrm{mL}$ and the mean prostate volume was $38.8 \pm 7.7(28-54) \mathrm{cc}$. The biopsy Gleason score ranged from 5 to 7 . The median follow-up period was 14 (3-30) months. Anastomotic stricture did not occur in any of the patients. Of the 9 patients, $4(44 \%)$ were immediately continent after catheter removal, while the remaining patients were continent at the end of three months. Of the 7 patients who underwent nerve-sparing surgery, 2 had postoperative spontaneous erections. Erectile function was maintained with phosphodiesterase 5 (PDE-5) inhibitor treatment in 3, and with intracavernosal injection in 1 patient. Penile prosthesis implantation was performed in 1 patient.

Conclusion: RPP has been a promising procedure at the start with its favorable oncologic and functional outcomes. This method should be considered by urologists, although it has been previously perceived as a challenging surgical procedure to perform.

Key words: Prostate cancer; radical perineal prostatectomy; radical prostatectomy.

\section{Introduction}

Radical prostatectomy (RP) is an effective curative treatment modality in organ-confined prostate cancer. As surgical treatment modalities, retropubic, perineal, laparoscopic, and robotic procedures have been applied. Essentially, minimally invasive treatment modalities as robotic, and laparoscopic radical prostatectomies use retropubic approach to prostate. From this aspect, perineal route differs from other methods. When historical development of radical perineal prostatectomy (RPP) was investigated, from its first application in the beginning of 1990s up to our time it has lead a fluctuating course. Hugh Hampton Young used perineal approach firstly in $1904^{[1]}$ however Belt described the subsphincteric route in $1942 .{ }^{[2]} \mathrm{Up}$ to the end of $1970 \mathrm{~s}$, perineal approach for radical prostatectomy was accepted as a less invasive method. ${ }^{[3]}$ Identification, and definition of periprostatic cavernosal nerves, and nerve-sparing radical retropubic prostatectomy (RRP) by Walsh in $1982^{[4]}$ which has been considerably adapted, and the mostly preferred method in the world. Even further definiton of nerve sparing surgery by Weldon in $1988^{[5]}$ did not decrease the interest in RRP. Introduction of laparoscopic radical prostatectomy (LRP) has increased interest in less invasive methods. During this period lower hospital costs, and morbidity rates have revived interest in RPP for the treatment of clinically localized prostate cancer. ${ }^{[6,7]}$ However, most of the young urologists prefer RRP because of their familarity with surgical anatomy. ${ }^{[8]}$ As young urologists, we wanted to raise awareness about less frequently preferred RPP which appears to be a difficult procedure to learn, and apply. To that end, we report out- 
comes of this method which we performed on our first patient series after we received its training.

\section{Material and methods}

A week-long RPP course was completed under the surveillance of expert specialists with the aid of audovisual documents. Live surgical training during, and after the completion of the course reinforced our knowledge about the procedure. Under the surveillance of expert specialist, trainees performed one-to -one RPP operations. After this training period, trainees performed RPP on 9 patients with localized prostate cancer between November 2011, and May 2013.

\section{Patient selection}

The patients were selected among cases with low risk group who did not require lymph node sampling (PSA $<10 \mathrm{ng} / \mathrm{mL}$, Gleason score $<7$ ). Patients with manifest chronic obstructive pulmonary disease or hip ankle ankylosis which would prevent placement of the patient in the exaggerated lithotomy position were excluded from the study. As starting cases, the patients with prostate volumes smaller than $60 \mathrm{cc}$, and those without marked median lobe were preferred. Informed consent forms were obtained from all patients.

\section{Surgical technique}

The method learnt during the courses was applied on all patients. Operation was started with a perineal ' $U$ ' shaped incision with the patient in the exaggerated lithotomy position. Denonvilliers' fascia was observed beneath the extensor anal sphincter and the surgery was proceeded through this route (Belt's route). Then rectourethral muscle was resected to approach to the prostate gland. Prostatic fascia covering the prostatic base was opened with blunt, and sharp dissection laterally to both directions, and intrafascial area was entered. Both vasa deferentia were sus- pended, and seminal vesicles were dissected up to their apexes. Then vasa deferentia, and both prostatic pedicles were ligated, and cut. During dissection of the prostatic apex, endopelvic fascia, and dorsal venous complex were dissected away from the urethra, and retracted upwards. Then urethral sphincter was resected from its distal part. Perforating vessels were brought under control in the anterior fibromuscular area, and circular fibers of the detrusor muscle were approached from 12 o'clock position. Prostate gland was held in traction using a Foley catheter, and separated from bladder neck using circumferential blunt, and sharp dissections. Prostate, and both seminal vesicles were removed en bloc. Urethra, and bladder neck were anastomosed using continuous waterproof sutures. On postoperative 2. day Penrose drain was removed, and the patients were discharged. On postoperative 10. day, Foley catheter, and skin sutures were removed.

\section{Results}

The patients were followed up for a median of 14 (3-30) months. Demographic, and clinical data of the patients were as follows: mean age, $60.4 \pm 5.3(50-68)$; mean preoperative PSA value, $5.8 \pm 1.3$ (4.0-7.6) $\mathrm{ng} / \mathrm{mL}$; mean prostate volume, $38.8 \pm 7.7$ (28-54) cc; total Gleason score, 6-7; mean operative period, $191.1 \pm 53.2(130$-300) mins; mean perioperative amount of blood loss, 330 \pm 192.6 (120-650) cc; mean hospital stay, $2.1 \pm 1.1$ days (Table 1 ).

Surgical margin negativity was detected in all histopathological specimens. As pathological grades, pT2a $(n=2)$, pT2b $(n=4)$, and pT2c $(n=3)$ were determined. At postoperative 1. month, PSA values ranged between 0.01 , and $0.09 \mathrm{ng} / \mathrm{mL}$. Though all patients had negative surgical margins, in one patient PSA recurrence $(1.02 \mathrm{ng} / \mathrm{mL})$ was seen at 14 . month of the followup period. Local recurrence or metastasis was not detected, and

\section{Table 1. Demographic data of the patient relevant to RPP}

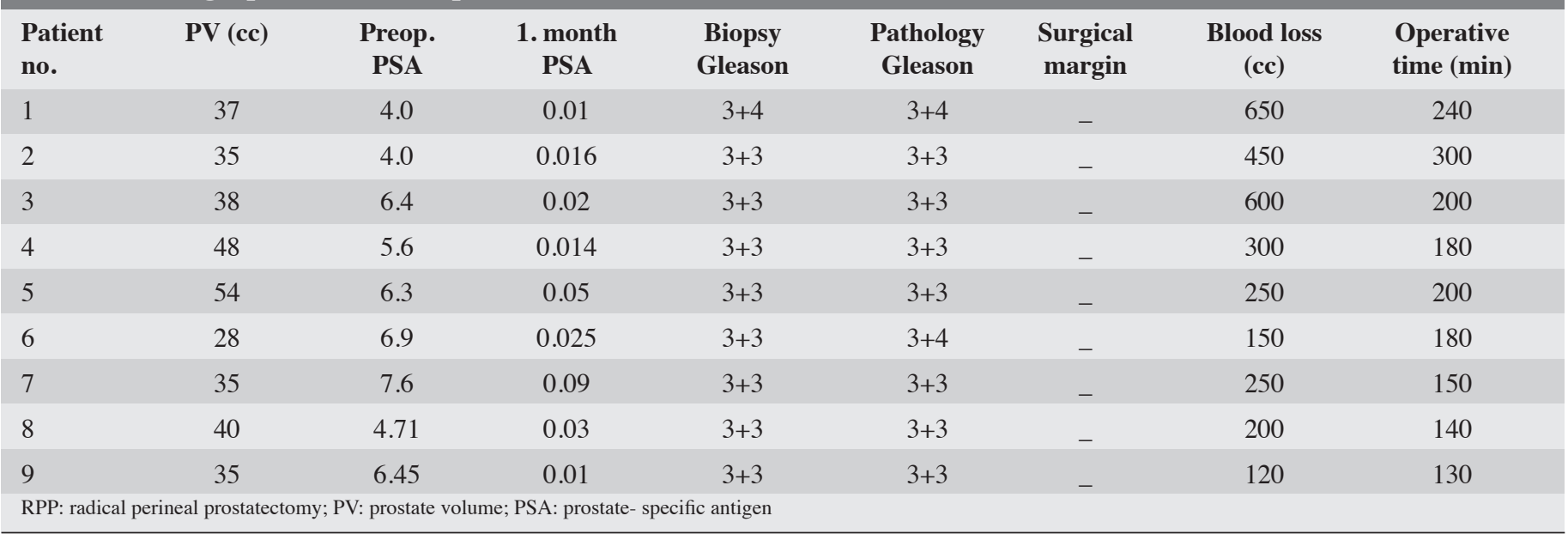


also PSA progression was not observed during the follow-up period.

Patient's urinary continence was evaluated at three time points namely at the time of removal of the urethral catheter, at 1., and 3. months. Four patients was continent at the time of catheter withdrawal, while 3 patients at the end of the first, and one patient at the end of the thirs month were completely dry. At the end of the third month, none of our patients used any pad. Since all patients were continent at an early phase, patients' continency was not classified at postoperative 6 . months and 1 . year, postoperatively.

None of the patients consulted with complaints of vesicourethral anastomotic stenosis or urethral stenosis. At 3. month controls, mean Qmax was 31.4 \pm 7.4 on uroflowmetry test.

Two patients without a preoperative history of coitus were considered to have erectile dysfunction, and nerve sparing surgery was not performed. In 2 of 7 patients who underwent bilateral nerve sparing surgery spontaneous erections were observed. Three patients responded to PD5 inhibitors, one patient maintained their erectile functions with intracavernosal injections. Penile prosthesis was implanted in one patient.

On postoperative 5. day, in one patient Foley catheter came out spontaneously, and it was reinserted through the urethra within 2 hours. One patient treated because of fat necrosis on the incision site, and wound care. Only one patient required blood transfusion. Rectal injury did not occur during perioperative period, besides fecal, and anal incontinence were not seen during the postoperative period.

\section{Discussion}

Though perineal approach was firstly used used for radical prostatectomy procedures, it was considered to be less invasive method up to the end of $1970 \mathrm{~s},{ }^{[3]}$ and nowadays it is less frequently preferred method. One of its reasons is that nervesparing anatomical RRP has gained worldwide acceptance since 1982, and from that time on lesser number of urologists have been trained on perineal prostatectomy. ${ }^{[7]}$ However many acknowledged advantages of this method based on many years of experience on larger patient series have been reported in the literature. ${ }^{[9-12]}$ Inherent to this method, deep dorsal veins are protected from surgical injury. In many studies, lesser amount of bleeding occurs in RPP relative to RRP. However some authors couldn't find any difference between LRP, and RPP as for amount of blood loss, and need for transfusion. ${ }^{[7]}$ In a study performed on 401 patients, significantly increased need for transfusion, longer hospital stay, and transurethral catheterization time were reported for RRP, when compared with RPP, and
LRP. The authors indicated that development of medical, and surgical complications was at a minimum level in RPP. ${ }^{[9]}$ In a series of 508 patients Harris ${ }^{[10]}$ defined modified nerve-sparing surgery, and described RPP as a minimally invasive effective method with its improved functional outcomes, and lower hospital expenditures. In our study, mean hospital stay was $2.1 \pm 1.1$ days, and only 9 patients required one unit whole blood transfusion which were in compliance with our literature findings. Besides, apart from a patient who had previously undergone anal fissure repair, surgical dissections were easy to perform without development of any major complication.

When major complications of radical prostatectomy were considered, anastomotic stenosis is less frequently seen in RPP relative to RRP. ${ }^{[10,11]}$ This phenomenon might be related to relative ease of performing urethral dissection, and vesicourethral anastomosis through perineal approach. ${ }^{[10]}$ In our study, during the follow-up period urethral or anastomotic stenosis did not develop in any one of our patients.

Harris ${ }^{[10]}$ in his RPP series reported continence, mild stress, and other types of urinary incontinence in $96,2.5$, and $1.5 \%$ of their patients, respectively. However in another study, early postoperative incontinence was emphasized, and a $36.7 \%$ incidence rate was reported for "immediate postoperative incontinence" which especially occurs soon after removal of the urethral catheter. ${ }^{[12]}$ While, some studies have not detected any difference between RRP, and RPP as for rates of incontinence. ${ }^{[13]}$ In our study 4 (44\%) patients were continent immediately after withdrawal of the urethral catheter, and all of our patients were "dry" at 3 postoperative months.

In the literature, when compared with RRP, advantages of RPP including lower amount of blood loss, shorter hospital stay, decreased hospital expenditures, ease of applicability in obese patients or those with a history of abdominal surgery, and lesser postoperative pain have been reported. In addition its disadvantages have been also cited. Need for a separate incision for pelvic lymphadenectomy, unsuitability for larger prostates $(\geq 80$ cc) deep, and narrow surgical field provided for the surgical manipulations of the surgeon and impossibility to place patients with a hip problem in an exaggerated lithotomy position restrict the number of patients eligible for RPP. Besides among its disadvantages, requirement for a longer learning curve, and higher incidence of rectal injury during RPP are enumerated. ${ }^{[14,15]}$

In our study, scarce number of our patient population, shorter follow-up period (mean 14 months), and failure to compare perineal RP with any other RP techniques are limitations of our study.

In conclusion, nowadays, enormous, and exciting rise of robotic surgery which overshadowed even laparoscopic procedures, and 
because of perceived difficulty of learning perineal approach, RRP seems to rank at the end of the scale of preference of the urologists. However during the first years of our learning curve, achievement of continence in the early postoperative period, and absence of anostomotic stenosis have encouraged us for the maintenance of this method. Therefore we think that RPP is an easily applicable procedure by urologists with its shorter learning curve, and successful functional results.

Ethics Committee Approval: Due to the retrospective study design, ethics committee approval was not necessary.

Informed Consent: Written informed consent was obtained from patients who participated in this study.

Peer-review: Externally peer-reviewed.

Author Contributions: Concept - M.G.; Design - M.G., M.A.; Supervision - M.U., M.A.; Funding - M.G., M.A.; Materials - M.G.; Data Collection and/or Processing - M.G., M.A., F.U., B.A.; Analysis and/or Interpretation - M.G., M.A., F.U., B.A.; Literature Review - M.G., M.A.; Writer - M.G.; / Critical Review - M.G., M.A., F.U., B.A., M.U.

Acknowledgments: We want to thank to Prof. Dr. Selami Albayrak, $\mathrm{MD}$, for selfless support during our training period about radical perineal prostatectomy.

Conflict of Interest: None declared

Financial Disclosure: The authors declared that this study has received no financial support.

\section{References}

1. Young H. The early diagnosis and radical cure of carcinoma of the prostate. J Urol 1905;16:315-21.

2. Belt E. Radical perineal prostatectomy in early carcinoma of the prostate. J Urol 1942;78:287-97.

3. Frazier HA, Robertson JE, Paulson DF. Radical prostatectomy: the pros and cons of the perineal versus retropubic approach. J Urol 1992;147:888-90.
4. Walsh PC, Donker PJ. Impotence following radical prostatectomy: insight into etiology and prevention. J Urol 1982;128:492-7.

5. Weldon VE, Tavel FR. Potency-sparing radical perineal prostatectomy: anatomy, surgical technique and initial results. J Urol 1988;140:559-62.

6. Theodorescu D, Lippert MC, Broder SR, Boyd JC. Early prostatespecific antigen failure following radical perineal versus retropubic prostatectomy: the importance of seminal vesicle excision. Urology 1998;51:277-82.

7. Holzbeierlein JM, Porter HJ 2nd, Thrasher JB. The craft of urologic surgery: modern radical perineal prostatectomy. Urol Clin North Am 2004;31:629-41.

8. Salomon L, Levrel O, Anastasiadis AG, Saint F, de La Taille A, Cicco A, et al. Outcome and complications of radical prostatectomy in patients with PSA $<10 \mathrm{ng} / \mathrm{ml}$ : comparison between the retropubic, perineal and laparoscopic approach. Prostate Cancer Prostatic Dis 2002;5:285-90.

9. Salomon L, Levrel O, de la Taille A, Anastasiadis AG, Saint F, Zaki S, et al. Radical prostatectomy by the retropubic, perineal and laparoscopic approach: 12 years of experience in one center. Eur Urol 2002;42:104-10.

10. Harris MJ. Radical perineal prostatectomy: cost efficient, outcome effective, minimally invasive prostate cancer management. Eur Urol 2003;44:303-38.

11. Gillitzer R, Thomas C, Wiesner C, Jones J, Schmidt F, Hampel $\mathrm{C}$, et al. Single center comparison of anastomotic strictures after radical perineal and radical retropubic prostatectomy. Urology 2010;76:417-22.

12. Albayrak S, Canguven O, Goktas C, Cetinel C, Horuz R, Aydemir $\mathrm{H}$. Radical perineal prostatectomy and early continence: outcomes after 120 cases. Int Braz J Urol 2010;36:693-9.

13. Kafkaslı A, Boz MY, Balaban M, Horuz R, Selimoğlu A, Albayrak $\mathrm{S}$, et al. The effects of retropubic and perineal radical prostatectomy techniques on urinary continence after surgery: Results of 196 patients. Turkish Journal of Urology 2013;39:147-52.

14. Prasad SM, Gu X, Lavelle R, Lipsitz SR, Hu JC. Comparative effectiveness of perineal versus retropubic and minimally invasive radical prostatectomy. J Urol 2011;185:111-5.

15. Gillitzer R, Thüroff JW. Relative advantages and disadvantages of radical perineal prostatectomy versus radical retropubic prostatectomy. Crit Rev Oncol Hematol 2002;43:167-90. 